\title{
Research on the Improvement of Supply Chain Management Under Drop-shipping Model
}

\author{
Zhang Lu \\ School of Economics and Management \\ Beijing Jiaotong University \\ Beijing, China, 100044 \\ 18932520220@163.com
}

\begin{abstract}
As the rapid development of E-commerce leads to a new channel operation model, named drop-shipping model. But there still lacking of the related research, and most of the related researches is qualitative study. The paper analyzes the characteristics and advantages of the drop-shipping basic model using the wholesale price contract compared with the traditional model in which the retailers hold the inventory from the perspective of quantitative. The study introduce improvement of supply chain management under drop-shipping model and gives a further research direction.
\end{abstract}

Keywords-Drop-shipping; E-commerce; Performance; Supply chain management; Improvement

\section{INTRODUCTION}

The Drop-shipping model is developed after the rise of ecommerce. The traditional model is ordered by the retailer to the supplier before the start of the production. At the beginning of the sale, suppliers deliver the product and retailers hold the stock after the goods are handed over, so that the supplier and the retailer will have some stock. Consumers buy products from retailers, and retailers allocate products in their own inventory for delivery, and ultimately deliver products to consumers, and retailers only order the time before order to produce order information to the supplier, supply Businessmen will not be in direct contact with the final consumer [1].

In contrast to the traditional model, the Drop-shipping model is the retailer to accept the order of the consumer, the order information will be forwarded directly to the supplier, the supplier in their own inventory in the distribution of products for distribution, the supplier will eventually send the product. In the hands of consumers, the product does not need to be transported by the retailer, and the retailer does not always have to hold the actual product inventory, in which retailers and suppliers are in direct contact with the consumer. In the Drop-shipping model, the use of different options will exist in different order mode, in the most basic wholesale price contract, before the start of production by the supplier according to market conditions to determine the optimal production, and retailers only need to sell. After the start of the consumer's order information forwarded to the supplier, retailers have nothing to do on the production and decision-making. On the corresponding, under the using of wholesale price contract, the inventory risk will be borne entirely by the supplier, retailers

Corresponding Author: Lu Zhang

School of Economics and Management, Beijing Jiaotong University, Beijing, 100044 China

18932520220@163.com. no longer bear any inventory risk. In this case, the wholesale price of the product is often higher than the traditional model of wholesale prices, so that retailers will some compensation to suppliers.

\section{LITERATURE REVIEW}

As the Internet appeared earlier in foreign countries, ecommerce also appeared relatively long, followed by the birth of Drop-shipping model also appeared earlier, the first study focused on qualitative analysis, with the gradual maturity of the study began Scholars do quantitative analysis of the supply chain under the direct supply model of consignment sales.

Khouja (2001) pointed out that in the Drop-shipping model of consignment sales, the inventory holding cost and the remaining product processing cost are lower, but the supply problem is not timely [2]. Therefore, it is considered that the mixed supply chain model should be used for retailers. In the study, we designed a hybrid strategy and gave the results under different distributions. However, this strategy is not suitable for the enterprise to adopt in some cases, especially when the retailer's strength is low and the risk is aversion is not practical.

Netessine and Rudi (2006) researched on the problem of supply chain selection when there exists one supplier and several retailers is studied [3]. The research points out that the traditional model and Drop-shipping model model are both popular, but the inventory decision-making under these two models, the allocation of inventory risk and the profit distribution among the members of the supply chain will be different. Through the research, we give the condition that the Drop-shipping model is better than the traditional model. In the direct sales model, the inventory of many retailers concentrates on the supplier, which will reduce the marginal cost of the product and the scale effect. Can reduce supply chain inventory risk. In addition, the supply chain performance is improved by adopting a hybrid model that combines the Drop-shipping model of consignment with the traditional one. In the hybrid strategy, the traditional model is the main supply mode while the Drop-shipping model is used as the backup supply Way of delivery [4]. This hybrid strategy still has problems that are not suitable for certain scenarios, especially for small and mediumsized enterprises.

Yan (2009) introduced the characteristics of Drop-shipping model, qualitatively analyzes the Drop-shipping model and the 
traditional model and direct selling model, and analyzes the direct supply and demand relationship between consignment supply and direct supply from the perspective of the external environment, Mode for the development of cooperation between the two sides for the advantages of policy, on the basis of qualitative from the perspective of the proposed cooperation between suppliers and retailers in this strategy.

Xie (2013) pointed out that the Drop-shipping model is beneficial to both suppliers and retailers. In the Drop-shipping model, suppliers can expand sales, grasp more consumer information, and more timely grasp of market trends; the same time, retailers can zero inventory costs in the conditions of product sales, in marketing work. For the first time, based on the selection index of suppliers in the traditional supply chain, combined with the characteristics of the Drop-shipping model, this paper proposes a set of supplier selection criteria for Dropshipping model, including profit margin, quality, delivery, etc.

At present, the researches on consignment sales in China still remain in the qualitative analysis, lack of quantitative analysis [5]. In the only quantitative analysis, there is also no solution to the problem of supply chain coordination. New problems in the cooperation between suppliers and retailers are not considered. The paper will carry on the research to these questions and definite the research direction of this topic.

\section{ADVANTAGES OF DROP-SHIPPING}

Compared with the traditional model, from various perspective, the Drop-shipping model has many advantages:

\section{A. Reduce retailers' risk, improve sales ability}

In the e-commerce environment, many retailers due to its low entry threshold, low input and low risk to join the sales area. Drop-shipping model almost meet all the requirements of such retailers. In this model, retailers do not own product inventory, basically do not assume any risk, and also needn't to focus on inventory management or pay inventory funds. At the same time, without considering the logistics and distribution, greatly streamlining on the retailer's work will help retailers to focus on the improvement of sales ability and product promotion.

\section{B. Improve suppliers' operation and product sales}

In the Drop-shipping model, the supplier is responsible for the order fulfillment. They will complete logistics and distribution work, the product can be delivered directly to consumers and also can directly contact a wider range of consumers then quickly obtain consumer information [6]. Further analysis of market changes is conductive to the supplier's macro-operation control, auxiliary product update design and the improvement of the supplier's market resilience. In addition, due to avoidance of the retailer transport links and reduce the causes of supply chain breaks and bullwhip effect intensified, improve the operation of suppliers ability.

When the price of some products changes the risk or new products have not been promoted yet, if we adopt the traditional model, retailers tend to be forced to give up the product sales because of high risk and the product is difficult to promote. However, if we use the Drop-shipping model, retailers can avoid the risk, and only based on sales to obtain the appropriate commission. Then they often willing to sell the products, suppliers can achieve the purposes of the products promotion.

In e-commerce environment, many retailers due to economic strength and other reasons, can not provide a high level of logistics and distribution services to a certain extent, which limit the increase in product sales. While in the Dropshipping model, the supplier can use the scale effect to reduce the unit product of the distribution costs. It is relative to the retailers, suppliers often have the strength to provide consumers with a high level of logistics and distribution services to consumers a good shopping experience. Then react to the product sales, and improve product sales.

\section{Strengthen the two sides' cooperation to achieve channel optimization}

In the Drop-shipping model, the retailer transfers the responsibility for inventory and order fulfillment to the supplier. The supplier uses the inventory and logistics distribution to improve the operational capacity [7]. The retailer and the supplier realize the separation of the logistics and the information flow, but the supplier and retailers to further strengthen the relationship between each other, the transaction process more emphasis on the joint cooperation between the two sides.

Increasing the profitability of suppliers depends on the retailer's efforts. Suppliers need retailers to actively carry out product marketing and improve product sales. To a certain extent, the more retailers can result in the higher the sales volume and the profits of the produces [8].

The increase in retailer profits depends on the supplier's efforts. The retailer transfers the responsibility for inventory and order fulfillment to the supplier, concentrating on improving the sales ability, and the retailer's efforts can be rewarded when the supplier does a good job of logistics and distribution services and gives consumers a good shopping experience [9].

With the joint efforts of retailers and suppliers, it is benefit to reduce the unbalanced factors in the traditional model. Meanwhile, it is also possible to adjust the operation strategy of the upstream and downstream enterprises in the supply chain, and reduce the information asymmetry in the supply chain, also can reduce the risk and uncertainty and promote product sales into a virtuous circle [10].

\section{IMPROVEMENT OF SUPPLY CHAIN PERFORMANCE UNDER DROP-SHIPPING MODEL}

The paper considers a secondary supply chain consisting of a single supplier and a single retailer, the supply chain is primarily engaged in the sale of a single commodity. Assuming that the supply chain operates in a newsboy environment, the so-called newsboy environment is a product that is not sold in any period and can not be sold again in the future sales cycle, while there is a surplus value. The retailer is out of stock order, and the market demand for the same period is independent with the distribution.

Under this assumption, the multi-cycle problem has been successfully turned into a single-cycle problem. In addition, the 
paper takes into account the two modes of operation of the supply chain. The traditional model (the retailer holding the inventory and responsible for the logistics of consumers) and Drop-shipping model (the supplier holding inventory and responsible for the logistics of consumers). We consider the supply chain model under the basic Drop-shipping model, that is, the supply chain model with the wholesale price contract. The symbols are shown in Table 1:

TABLE I. VARIABLE DESCRIPTION

\begin{tabular}{|c|c|c|c|c|}
\hline \multirow[b]{2}{*}{ No. } & \multicolumn{4}{|c|}{ Variable Description } \\
\hline & Variable & Explanation & $\begin{array}{l}\text { Variabl } \\
e\end{array}$ & Explanation \\
\hline 1 & $c$ & $\begin{array}{l}\text { Production cost for } \\
\text { per unit }\end{array}$ & $r$ & $\begin{array}{l}\text { Retailer unit sales } \\
\text { price }\end{array}$ \\
\hline 2 & $v_{r}$ & $\begin{array}{l}\text { Price of retailer's } \\
\text { remaining product }\end{array}$ & $v_{s}$ & $\begin{array}{l}\text { Price of supplier's } \\
\text { remaining product }\end{array}$ \\
\hline 3 & $\pi_{r}$ & Profit of retailers & $\pi_{s}$ & Profit of suppliers \\
\hline 4 & $\Pi$ & $\begin{array}{l}\text { Total profit of supply } \\
\text { chain }\end{array}$ & $\wedge$ & $\begin{array}{l}\text { Represents the } \\
\text { traditional model }\end{array}$ \\
\hline 5 & $\omega$ & $\begin{array}{c}\text { Wholesale price } \\
\text { under traditional } \\
\text { model }\end{array}$ & $\omega_{d}$ & $\begin{array}{l}\text { Wholesale price } \\
\text { under drop- } \\
\text { shipping model }\end{array}$ \\
\hline 6 & $q$ & Yield of products & $\Delta$ & difference \\
\hline 7 & $f(x)$ & $\begin{array}{l}\text { Demand density } \\
\text { function }\end{array}$ & $F(x)$ & $\begin{array}{l}\text { Demand } \\
\text { distribution } \\
\text { function }\end{array}$ \\
\hline
\end{tabular}

In the market, the consumer's demand for product $\mathrm{x}$ is a random variable, the demand density function and the distribution function are $\mathrm{f}(\mathrm{x}), \mathrm{F}(\mathrm{x})$. Retailers sell goods at the retailing price $r$, which already contains the cost of shipping the product to the consumer, while the cost of the supplier's production unit product is c. In the traditional model, the retailer has the dominance, and the number of orders for the cycle is determined at the beginning of each cycle (* indicates the optimal order quantity for the retailer in the traditional mode). In the traditional model, the retailer buys the product from the supplier at a wholesale price of $\omega$. The decisionmaking process of suppliers, retailers and consumers in the traditional model is shown in Figure 1.

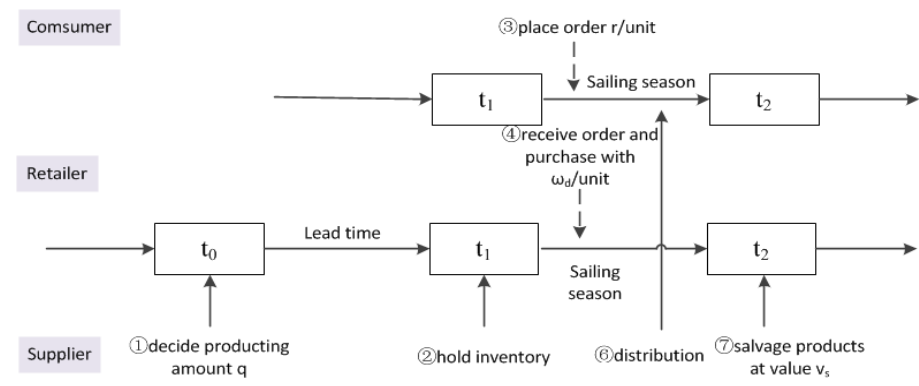

Fig. 1 Traditional model

If the wholesale price contract is used in the Drop-shipping model, the supplier will have the dominance in the supply chain. The number of productions determined by the supplier at the beginning of each cycle is $\hat{\mathrm{q}}$ ( $\hat{\mathrm{q}}$ *represents the optimal production of the supplier in the consignment direct supply mode). Since the supplier is responsible for the order fulfillment and bear the risk of the stock in the Drop-shipping model, the retailer should pay the supplier a higher unit wholesale price. In practice, the price of the supplier's products under the Drop-shipping model is higher than that of the traditional model of $10 \%$ to $20 \%$. Therefore, if we assume that the wholesale price of the supplier's product is $\omega_{d}, \omega_{d}>\omega$, (d is the retailer's risk compensation to the supplier). In addition, suppose that the supplier is in a highly competitive environment, the supplier must accept any number of retailers direct sales request, otherwise the retailer will turn to other suppliers. In addition, the supplier did not separate the decision ability on $\omega$ and $\omega_{d}$. The decision-making process of suppliers, retailers and consumers is shown in Fig. 2 when the simple wholesale price contract is used in the Drop-shipping model.

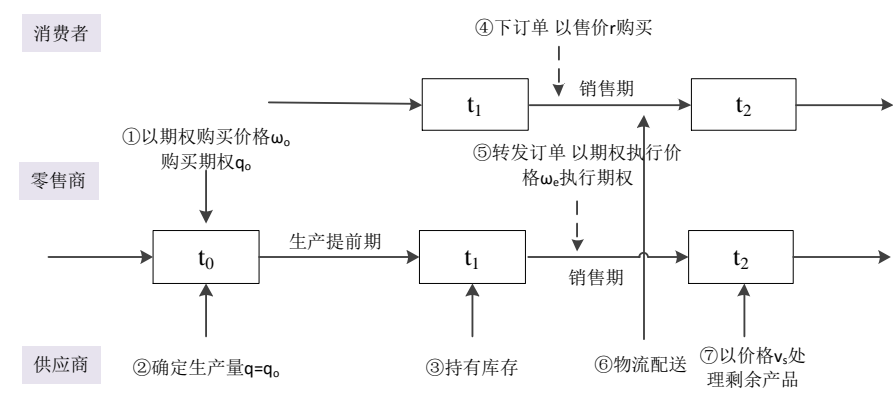

Fig. 2 Drop-shipping model

Combine with the analysis above, in the traditional model, profit of retailer $\hat{\pi}_{r}(q)$ is

$$
\hat{\pi}_{r}(q)=-\omega q+r S(q)+v_{r}(q-S(q))
$$

The profit of supplier $\hat{\pi}_{s}(q)$ is

$$
\hat{\pi}_{s}\left(q^{*}\right)=(\omega-c) q^{*}
$$

The profit of supply chain is

$$
\hat{\Pi}\left(q^{*}\right)=-c q^{*}+r S\left(q^{*}\right)+v_{r}\left(q^{*}-S\left(q^{*}\right)\right)
$$

The following figure directly shows the profit of retailer, supplier and the whole supply chain.

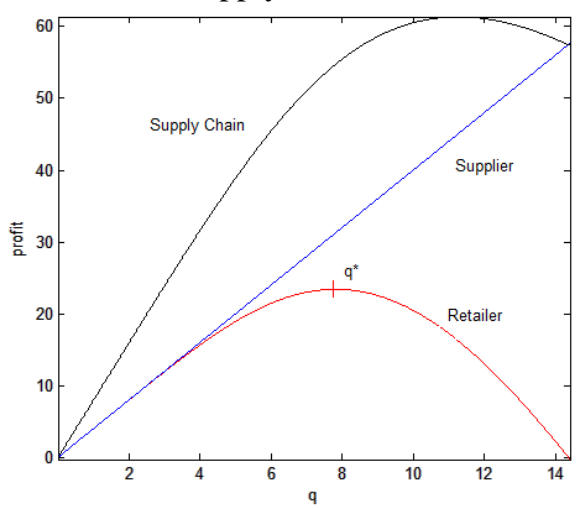

Fig. 3 Profit under the traditional model

While in the Drop-shipping model, the profit of retailer is

$$
\pi_{r}\left(q^{*}\right)=\left(r-\omega_{d}\right) S\left(q^{*}\right)
$$

Profit of supplier is 


$$
\pi_{s}(q)=-c q+\omega_{d} S(q)+v_{s}(q-S(q))
$$

The profit of supply chain is

$$
\Pi\left(q^{*}\right)=-c q^{*}+r S\left(q^{*}\right)+v_{s}\left(q^{*}-S\left(q^{*}\right)\right)
$$

The following figure directly shows the profit of retailer, supplier and the whole supply chain under Drop-shipping model.

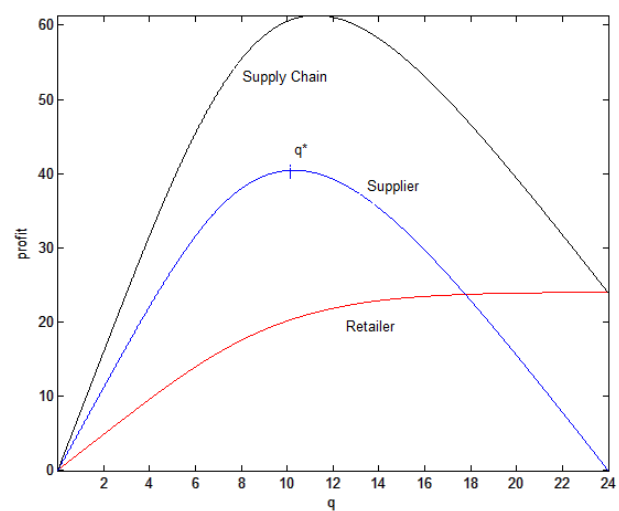

Fig. 4 Profit under drop-shipping model

The paper proves the improvement of the supply chain management under Drop-shipping model through an example. With the above models, we make some assumptions.

$$
\begin{aligned}
& r>\omega_{d} \geq \omega>c>\max \left(v_{s}, v_{r}\right) \geq 0 \\
& r=12 \\
& c=4 \\
& \omega=8 \\
& v_{r}=v_{s}=0 \\
& x \sim \Gamma(5.85 .1 .71)
\end{aligned}
$$

\section{$1 \leq k<1.5$}

When we place the assumptions into the model, we can get the optimal yield curve that describes the optimal yield between the supply and demand sides according to the expected return.

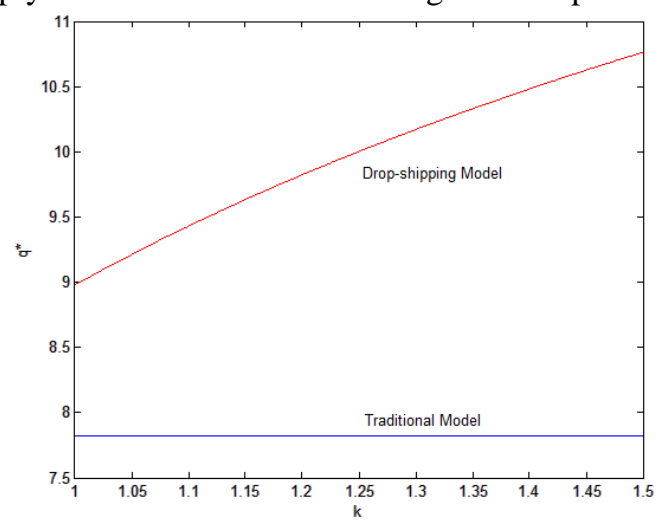

Fig. 5 Optimal production capacity under the two models

In the traditional model, as it is a single supplier and a single retailer model, suppliers need to meet the demand of retailers and make the product is not excessive. The production of the product is determined equal to the retailer's optimal order quantity. When the distribution of the demand variable $\mathrm{x}$ has been completely determined, the optimal order quantity determined by the retailer is certain, which is shown in the figure as a straight line parallel to the horizontal axis.

Under the Drop-shipping model, if the contract of wholesale price is used, it is up to the supplier to determine the optimal production quantity of the product. The optimal output of the product is affected by the wholesale price $\omega_{d}$. From the perspective of maximizing the supplier's own profit, as the kvalue increases, the optimal product yield expected by the supplier will show an increasing trend. From the retailer's point of view, we can see that the retailer increases the sales ability of the retailer and improves the sales volume of the product by shifting the risk and focusing more on the sales.

The following figure is the profit of the whole supply chain under the two models.

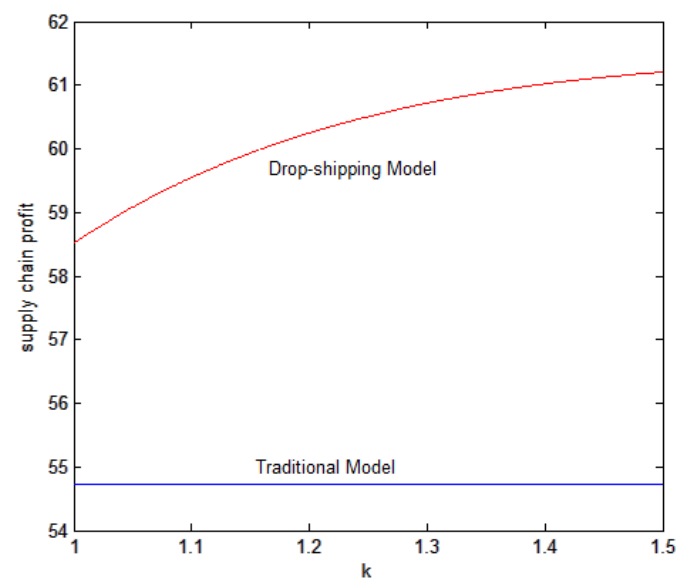

Fig. 6 Profit of the supply chain under the two models

The following figure shows the profit of the retailer and supplier under the two models.

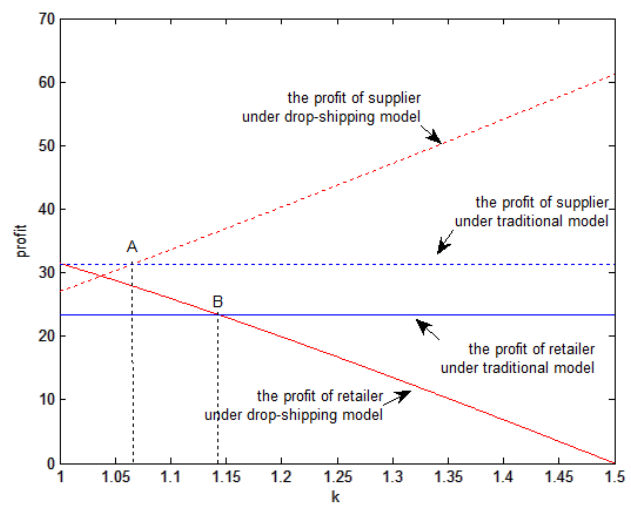

Fig. 7 Profit of the supplier or the retailer under the two models

From the above figures, the retailer has the following three conditions:

(1) The retailer's profit is higher than the traditional model after using Drop-shipping model, that is, between A and B, $\mathrm{k}$ is 
in the range of $[1.066,1.144]$, the two parties achieve "winwin" directly through Drop-shipping model.

(2) After adopting direct supply model, although the retailer's profit is lower than that of the traditional model, the total profit of the supply chain is higher than the traditional model, so a revenue sharing strategy can be used to evaluate the retailer Re-distribution with the supplier's profit, so that the retailer's profit rise, but also to ensure that the supplier's profit is not lower than the traditional model, otherwise the supplier will not agree to the implementation of revenue sharing strategy, that is, the right area $\mathrm{B}$, When $\mathrm{k}$ is located in the interval[1.144,1.5], both parties achieve "win-win" through profit sharing.

(3) If we adjust the parameter setting of the example, the profit of the supply chain will be lower than the traditional model. When the total profit of the supply chain is not higher than the traditional model in the Drop-shipping model, in some cases retailers can also increase their own profits by adopting other forms of contracts or even mixed options. This special case will the following sections are discussed in detail.

\section{CONCLUSION}

Through the establishment of the model, the paper studies the two sides chain model composed of a single supplier and a single retailer, and analyzes the realistic and feasible results of Drop-shipping model from the quantitative point of view. With the specific analysis, the main conclusions are as follows:

(1) Under the using of Drop-shipping model (wholesale price contract), although the retailer transfer the inventory risk to the supplier, the optimal production of the supply chain products increased. The paper proved Drop-shipping model can promote product sales and improve the capacity of retailing sales.

(2) The total profit of the supply chain in the Drop-shipping model is higher than that of the traditional model, indicating that the Drop-shipping model can play the role of improving the supply chain performance.

(3) In the Drop-shipping model, the existence of both supplier and retailer's profits is higher than the traditional model, that is, the two sides to achieve "win-win" in the profitability of suppliers under the premise .If the retailer's profit is not improved, but the total profits of the supply chain are improved, it is possible to achieve the two sides "win-win" through the revenue sharing strategy.
4) Both the traditional model and the Drop-shipping model can not achieve the coordination of supply chain. But compared with the traditional model, Drop-shipping model can improve supply chain performance.

In addition, although with the use of wholesale prices, we can achieve the two sides of the "win-win" to a certain extent, the scope of adjustment is limited. If we adjust the parameters, it is unable to achieve "win-win" situation. In the further research, we need to achieve supply chain coordination in order to achieve the total profit in the supply chain and implement the two sides "win-win".

\section{ACKNOWLEDGMENT}

Thanks are due to Professor Zhou for assistance with the valuable discussion. Thanks to Teacher Wang's guidance on the direction and enlightened me the new ideas.

\section{REFERENCES}

[1] Netessine S, Rudi N. Supply Chain Structures on the Internet: Marketing-Operations Coordination [J]. Social Science Electronic Publishing. 2000.

[2] Khouja M. The evaluation of drop shipping option for e-commerce retailers [J]. COMPUTERS \& INDUSTRIAL ENGINEERING. 2001, 41(2): 109-126.

[3] Netessine S, Rudi N. Supply Chain Structures on the Internet [J]. International. 2004.

[4] Netessine S, Rudi N. Supply Chain Choice on the Internet [J]. Management Science. 2006, 52(6):844-864

[5] Yao D Q, Kurata H, Mukhopadhyay S K. Incentives to reliable order fulfillment for an Internet. Drop-shipping supply chain [J]. International Journal of Production Economics. 2008, 113(1): 324-334.

[6] Chiang W K, Feng Y. Retailer or e-tailer? Strategic pricing and economic-lot-size decisions in a [8] competitive supply chain with dropshipping $[\mathrm{J}]$. Journal of the Operational Research Society. 2010, volume. [8]61(11): 1645-1653.

[7] Gan X, Sethi S, Zhou J. Commitment-Penalty Contracts in DropShipping Supply Chains with Asymmetric Demand Information [J]. European Journal of Operational Research. 2009, 204(3): 449-462

[8] Wang Q, Tang O, Tsao D B. A flexible contract strategy in a supply chain with an inflexible production mode [J]. International Journal of Operational Research. 2006, 1(3): 228-248.

[9] Cachon G P. The Allocation of Inventory Risk in a Supply Chain: Push, Pull, and Advance-Purchase Discount Contracts [J]. Management Science. 2004, 50(2): 222-238.

[10] Lee C C, Chu W H J. Who should control inventory in a supply chain? [J]. European Journal of Operational Research. 2005, 164(1): 158-172. 